\title{
Chemoradiation Compared to Surgery Alone in Patients With Non- Metastatic Esophageal Carcinoma
}

\author{
Mohamed I. El-Sayed $^{1} \&$ Doaa W. Maximous ${ }^{2}$ \\ ${ }^{1}$ Radiation Therapy Department, South Egypt Cancer Institute, Assiut University, Assiut, Egypt \\ ${ }^{2}$ Surgical Oncology Department, South Egypt Cancer Institute, Assiut University, Assiut, Egypt \\ Correspondence: Mohamed I. El-sayed, at the Department of radiation therapy, South Egypt Cancer Institute, \\ El-methak St; Assiut, Egypt. Tel: 20-12-295-3887; Fax: 20-88-234-8609. E-mail: mohebel@yahoo.co.uk
}

\author{
Received: October 14, 2014 Accepted: November 12, 2014 Online Published: November 26, 2014 \\ doi:10.5539/cco.v4n1p1 URL: http://dx.doi.org/10.5539/cco.v4n1p1
}

\begin{abstract}
Purpose: To assess overall survival (OS) of esophageal cancer patients treated either by esophagectomy or chemoradiation (CRT).

Methods: The medical records of patients with non metastatic esophageal cancer, treated with esophagectomy and those treated with concurrent CRT were analyzed. For all patients, files were reviewed for age, sex, tumor site and type, grade, disease stage and survival. The Log- rank test was used to examine differences in OS rates.

Results: The medical records of 90 patients were analyzed. After a median follow up of 20 months, 2-year OS rate for the whole group was $46 \%$. There was significant differences in 2-year OS in favor of patients treated by concurrent CRT (55.4\%) compared to those treated by surgery (31\%) ( $\mathrm{p}=0.016$, HR:1.96, 95\% CI: $1.13-3.38)$. Univariate analysis showed that patients in each treatment group, had comparable 2-year OS rates regarding patient's age, gender, pathologic subtype, and histologic grade ( $p>0.05)$. Disease stage in each group and tumor site in CRT group significantly affected OS rates $(\mathrm{p}<0.05)$.

Conclusions: Survival rates were statistically significant higher in patients treated with CRT than in those underwent esophagectomy. Prognostic factors that affected survival were disease stage in each treatment group and tumor site in CRT group.
\end{abstract}

Key words: Survival analysis, chemotherapy and radiotherapy, esophageal cancer

\section{Introduction}

Esophageal cancer is associated with a poor prognosis, with a 5-year survival rate of 16\% (Ries et al., 2008). Surgery was the main treatment option of esophageal carcinoma but resulted in dismal survival (Siewert et al., 2001). The addition of post-operative radiation therapy results in radiation sequels as gastritis in the pulled up gastric remnant (Fok et al., 1993), and anastomotic strictures in the irradiated patients (Zieren et al., 1995). The discouraging results of surgery and the need for more effective therapy led to the development of definitive chemo-radiation (CRT) for esophageal cancer (Neuner et al., 2009). Meta-analyses have confirmed that neoadjuvant CRT resulted in a significant survival benefit in patients with esophageal carcinoma (Gebski et al., 2007; Kranzfelder et al., 2011; Sjoquist et al., 2011). The radiosensitizing effect of chemotherapy and control of micro-metastatic disease justify addition of chemotherapy to radiation therapy (Shridhar et al., 2013) which can be given either concurrently or sequentially.

The advantage of CRT over radiation alone was demonstrated by a randomized trial from the Radiation Therapy Oncology Group (RTOG 8501) (Herskovic et al., 1992) and its updated analysis (Cooper et al.,1999), with a 5 -year survival rate of $26 \%$ for patients treated by CRT compared to $0 \%$ for those treated by radiation only. Chemoradiation given concurrently resulted in significant decrease in mortality $(\mathrm{HR}=0.73 ; 95 \% \mathrm{CI}, 0.64-0.84$; $P<.05$ ), with an absolute 2-year survival benefit of $4 \%$, and absolute reduction of local recurrence of $12 \%$ (Wong, \& Malthaner, 2006). On the other hand, sequential chemo-radiotherapy showed no significant benefit in survival or local control but significant toxicities (Shridhar et al., 2013). Standard dose (50.4 Gy in 5.5 weeks) CRT was compared to high-dose (64.8 Gy in 7 weeks) CRT, in a phase III trial (Minsky et al., 2002), that showed a comparable survival but higher mortality in the high dose arm. Therefore concurrent CRT with radiation dose of 50.4 Gy to treat gross tumor volume with a 5-cm craniocaudal margin was established as the 
standard of care for patients with esophageal cancer (Shridhar et al., 2013).

The aim of the present retrospective study was to report on survival analysis in Egyptian patients treated either by esophagectomy or chemoradiation.

\section{Methods}

\subsection{Study Subjects}

This retrospective study was carried out by analyzing medical records of patients with the pathological diagnosis of esophageal carcinoma (90 patients), seen at the Surgical oncology and Radiotherapy Departments, SECI, Assiut University during the period from January 01, 2007 until December 31, 2013. Treatment decision for each patient was obtained by tumor board and the study was approved by the institutional review board at our center.

For all patients, files were reviewed for age, sex, tumor site and type, histologic grade, initial stage of presentation (by multi-slice CT scan done for each patient), general condition of the patient (using ECOG performance status scoring system), applied treatment, and survival.

Eligible patients had histologically confirmed non metastatic squamous cell carcinoma, or adenocarcinoma, of the esophagus. Disease was limited to the esophagus and regional lymph nodes. Patients with documented distant metastases or endoscopically demonstrated invasion of the tracheobronchial tree were excluded. Patients were required to have an ECOG performance status of $\leq 2$. Patients were grouped into two groups. Group 1: patients treated with esophagectomy $(\mathrm{n}=29)$, Group 2: patients treated with concurrent chemoradiation $(\mathrm{n}=61)$.

\subsection{Surgical Techniques Used}

Twenty patients with lower third tumors were treated by subtotal esphagectomy (Ivor Lewis technique), where right thoracotomy was done to complete mobilization of the esophagus and create an intrathoracic anastomosis usually at the level of the azygous vein.

Nine patients with middle third tumours were treated by total osophagectomy, where right thoracotomy was done to complete mobilization of the esophagus. The stomach was brought through posterior mediastinum to the neck for anastomosis.

\subsection{Radiotherapy Techniques Used}

All patients were irradiated using 3-D planning technique. Reproducibility was assessed by orthogonal laser beams. Patients were CT-simulated and scanned in supine position. On each CT slice, planning target volume (PTV) was defined to encompass the tumor volume with 5-cm cranio-caudal margins and 2-cm radial margins. The supra- and infraclavicular and the lower cervical lymph nodes were also included in patients with carcinomas of the upper thoracic esophagus. Both lungs, heart, and spinal cord were contoured. Radiation therapy was delivered in two phases. In phase I, radiation therapy was given using anterior and posterior fields for a total dose of $40 \mathrm{~Gy}$ in 20 fractions in 4 weeks. In phase II, boost dose of $10 \mathrm{~Gy}$ in 5 fractions in one week was delivered via two anterior and two posterior oblique fields for patients with lesions in lower two thirds $(\mathrm{n}=51)$, and via two anterior oblique wedged fields for patients with lesions in upper third $(\mathrm{n}=10)$. Customized blocks were used to shape the treatment fields. Radiation therapy was delivered using linear accelerator (Semins Mevatron M2) with photon energy of $15 \mathrm{MV}$, (high energy beams were used to minimize dose in lung volumes within these large fields) with total dose of 50 Gy in 25 fractions over 5 weeks. Radiation dose calculation was done by a treatment planning system (CMS-XIO, Version 4.33.02), using Clarkson dose calculation algorithm. Daily prescription dose was 2 Gys specified at the isocenter. The $95 \%$ isodose encompassed the entire PTV. Beams-eye-view (BEV) displays were used to ensure optimal target volume coverage and normal tissue sparing. Dose-Volume-Histograms (DVHs) helped to select the most appropriate treatment plan with V20 Gy lung $<30 \%$, V40 Gy heart $<30 \%$, and a maximum spinal cord dose $<45$ Gy. Concurrently with radiotherapy, cisplatin (40 $\mathrm{mg} / \mathrm{m} 2$ per week) was administered weekly starting with the first day of radiation and continued throughout the whole radiation treatment duration.

\subsection{After-Therapy Monitoring}

Follow-up examinations were performed routinely monthly after treatment. Multi-slice CT scan chest and abdomen to detect disease relapse were done annually.

\subsection{Statistical Methods}

The study cutoff point was January, 01, 2014. Chi-square test was used to compare percentages of patients' characteristics in both treatment groups. Overall survival (OS) was defined as the interval from enrollment to the date of death from any cause or last follow-up. It was estimated using Graphed prism program. The Log- rank 
test was used to examine differences in OS rates in both groups. A value below 0.05 was considered significant.

\section{Results}

\subsection{Patients' Characteristics}

The medical records of 90 patients with esophageal cancer were analyzed. In the present study, the majority of patients were males $(n=60,66.7 \%)$, of $<60$ years of age $(n=53,58.9 \%)$, had grade II $(n=47,52.2 \%)$, esophageal squamous cell carcinoma $(\mathrm{n}=50,55.6 \%)$, in the lower third of the esophagus $(\mathrm{n}=52,57.8 \%)$, and had stage III disease $(\mathrm{n}=56,62.2 \%)$. There were no significant difference regarding distribution of patients in both esophagectomy and chemoradiation groups, according to patients' age at diagnosis, gender, pathologic subtype, histologic grade, disease stage, and tumor site (Table 1).

Table 1. Patients' characteristics in both treatment groups

\begin{tabular}{|c|c|c|c|}
\hline Variable & $\begin{array}{c}\text { Surgery }(\mathrm{n}=29) \\
\text { NO }(\%)\end{array}$ & $\begin{array}{c}\text { Chemoradiation }(\mathrm{n}=61) \\
\text { NO }(\%)\end{array}$ & $\mathrm{P}$ value \\
\hline Age & & & 0.18 \\
\hline$*<60$ years $(\mathrm{n}=53)$ & $20(69)$ & $33(54.1)$ & \\
\hline$* \geq 60$ years $(n=37)$ & $9(31)$ & $28(45.9)$ & \\
\hline Sex & & & 0.75 \\
\hline *Females $(\mathrm{n}=30)$ & $9(31)$ & $21(34.4)$ & \\
\hline${ }^{*}$ Males $(\mathrm{n}=60)$ & $20(69)$ & $40(65.6)$ & \\
\hline Pathology & & & 0.34 \\
\hline *Squamous carcinoma $(\mathrm{n}=50)$ & $14(48.3)$ & $36(59)$ & \\
\hline *Adenocarcinoma $(\mathrm{n}=40)$ & $15(51.7)$ & $25(41)$ & \\
\hline Grade & & & 0.33 \\
\hline * Grade I $(\mathrm{n}=19)$ & $6(20.7)$ & $13(21.3)$ & \\
\hline * Grade II $(\mathrm{n}=47)$ & $18(62)$ & $29(47.5)$ & \\
\hline * Grade III $(\mathrm{n}=24)$ & $5(17.3)$ & $19(31.2)$ & \\
\hline Disease stage & & & 0.39 \\
\hline * stage IIA $(n=19)$ & $9(31)$ & $10(16.4)$ & \\
\hline * stage IIB $(n=15)$ & $5(17.3)$ & $10(16.4)$ & \\
\hline * stage IIIA (n=34) & $10(34.4)$ & $24(39.3)$ & \\
\hline * stage IIIB $(n=22)$ & $5(17.3)$ & $17(27.9)$ & \\
\hline Site & & & 0.06 \\
\hline *Upper third $(\mathrm{n}=10)$ & 0 & $10(16.4)$ & \\
\hline * Middle third $(\mathrm{n}=28)$ & $9(31)$ & $19(31.2)$ & \\
\hline${ }^{*}$ Lower third $(\mathrm{n}=52)$ & $20(69)$ & $32(52.4)$ & \\
\hline
\end{tabular}

\subsection{Survival Analysis}

After a median follow up of 20 months (ranged from 2 to 51 months), 2-year OS rate for the whole group was $46 \%$. There was significant differences in 2-year OS in favor of patients treated by concurrent chemoradiation (55.4\%) compared to those treated by surgery (31\%) ( $\mathrm{p}=0.016$, HR: 1.96, 95\% CI: 1.13-3.38) (Figure 1).

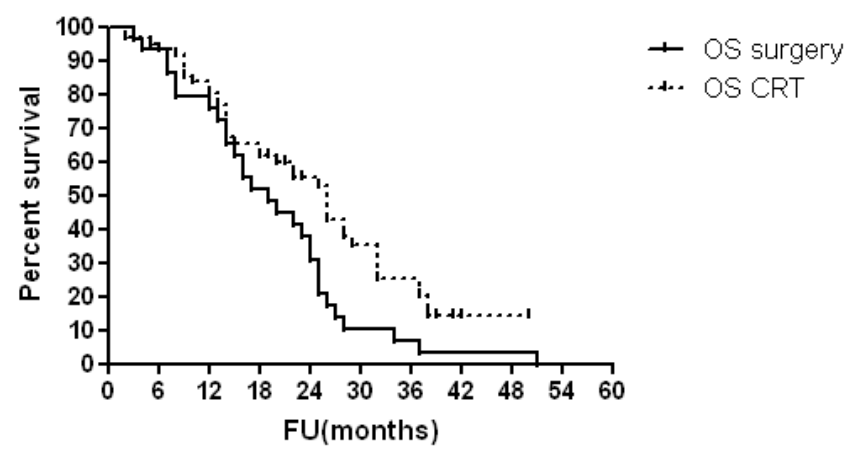

Figure 1. OS rare of patients in surgery group compared to that in CRT group 
In the present study, univariate analysis showed that patients treated by esophagectomy had comparable 2-year OS rates regarding patient's age ( $\mathrm{p}=0.12$, HR: $0.42,95 \%$ CI: $0.14-1.26)$, gender $(\mathrm{p}=0.64$, HR: $1.22,95 \%$ CI: $0.52-2.86$ ), pathologic subtype ( $\mathrm{p}=0.77$, HR:1.12, 95\% CI: $0.52-2.41)$, and histologic grade $(\mathrm{p}=0.87)$. Tumor site showed a trend of survival advantage in favor of middle third lesions ( $\mathrm{p}=0.066$, HR: $0.48,95 \%$ CI: $0.22-1.05$ ). Disease stage was the only prognostic factor that significantly affect OS rate $(\mathrm{p}=0.0029)$. In the chemoradiation group, patients' age ( $\mathrm{p}=0.2$, HR: $0.66,95 \% \mathrm{CI}: 0.34-1.26)$ and $\operatorname{sex}(\mathrm{p}=0.95$, HR: $1.02,95 \% \mathrm{CI}: 0.52-2.0$ ), pathology ( $\mathrm{p}=0.11$, HR: $0.41,95 \%$ CI: $0.20-0.81)$, and grade $(\mathrm{p}=0.32)$ did not significantly affect $\mathrm{OS}$ rate. Disease stage $(\mathrm{p}<0.0001)$ and tumor site $(\mathrm{p}=0.009)$ were the prognostic factors that significantly affect OS rate (Table 2 and Figures 2 and 3).

Table 2. Univariate analysis of factors that might affect OS in patients in both treatment groups

\begin{tabular}{|c|c|c|c|}
\hline \multirow[t]{2}{*}{ Variable } & & Surgery $(n=29)$ & Chemoradiation $(\mathrm{n}=61)$ \\
\hline & & 2-year OS (\%) & 2-year OS (\%) \\
\hline \multicolumn{4}{|l|}{ Age } \\
\hline$*<60$ years & $(n=53)$ & 36.4 & 56.5 \\
\hline$* \geq 60$ years & $(n=37)$ & 14.3 & 48.7 \\
\hline \multirow[t]{2}{*}{ Pvalue } & & 0.12, HR:0.42, 95\% CI: & 0.2, HR:0.66, 95\% CI: $0.34-1.26$ \\
\hline & & $0.14-1.26$ & \\
\hline \multicolumn{4}{|l|}{ Sex } \\
\hline *Females & $(n=30)$ & 22 & 61.1 \\
\hline *Males & $(\mathrm{n}=60)$ & 35 & 52.9 \\
\hline \multirow[t]{2}{*}{ Pvalue } & & 0.64, HR:1.22, 95\% CI: & 0.95, HR: $1.02,95 \%$ CI: $0.52-2.0$ \\
\hline & & $0.52-2.86$ & \\
\hline \multicolumn{4}{|l|}{ Pathology } \\
\hline \multicolumn{2}{|c|}{ *Squamous carcinoma $(\mathrm{n}=50)$} & 35.7 & 64.4 \\
\hline *Adenocarcinoma & $(\mathrm{n}=40)$ & 26.7 & 35.4 \\
\hline \multirow[t]{2}{*}{ Pvalue } & & 0.77, HR:1.12, 95\% CI: & 0.11, HR: $0.41,95 \%$ CI: $0.20-0.81$ \\
\hline & & $0.52-2.41$ & \\
\hline \multicolumn{4}{|l|}{ Grade } \\
\hline * Grade I & $(\mathrm{n}=19)$ & 16.7 & 50.5 \\
\hline * Grade II & $(n=47)$ & 33.3 & 68.1 \\
\hline * Grade III & $(n=24)$ & 40 & 40.6 \\
\hline Pvalue & & 0.87 & 0.32 \\
\hline \multicolumn{4}{|l|}{ Disease stage } \\
\hline * stage IIA & $(n=19)$ & 66.7 & 88.9 \\
\hline$*$ stage IIB & $(n=15)$ & 40 & 90 \\
\hline * stage IIIA & $(n=34)$ & 10 & 50 \\
\hline * stage IIIB & $(n=22)$ & 0 & 21.2 \\
\hline Pvalue & & 0.0029 & $<0.0001$ \\
\hline \multicolumn{4}{|l|}{ Site } \\
\hline *Upper third & $(\mathrm{n}=10)$ & - & 64 \\
\hline * Middle third & $(\mathrm{n}=28)$ & 36.6 & 73.7 \\
\hline * Lower third & $(\mathrm{n}=52)$ & 11.1 & 36.5 \\
\hline \multirow[t]{2}{*}{ Pvalue } & & 0.066, HR:0.48, 95\% CI: & 0.009 \\
\hline & & $0.22-1.05$ & \\
\hline
\end{tabular}




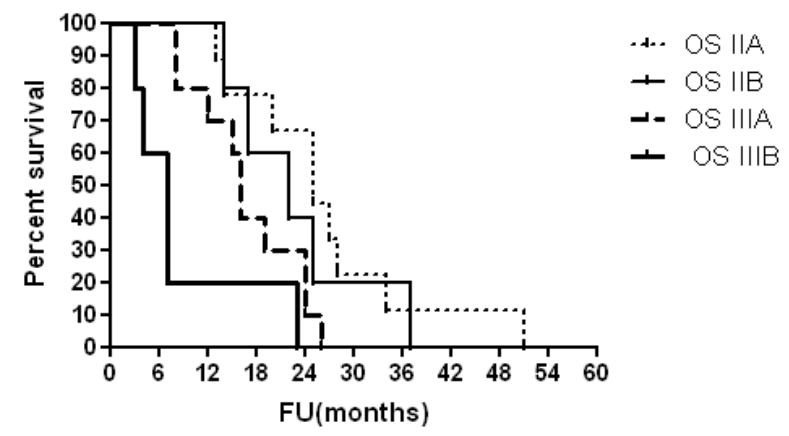

Figure 2. OS of patients who underwent esophagectomy with respect to disease stage

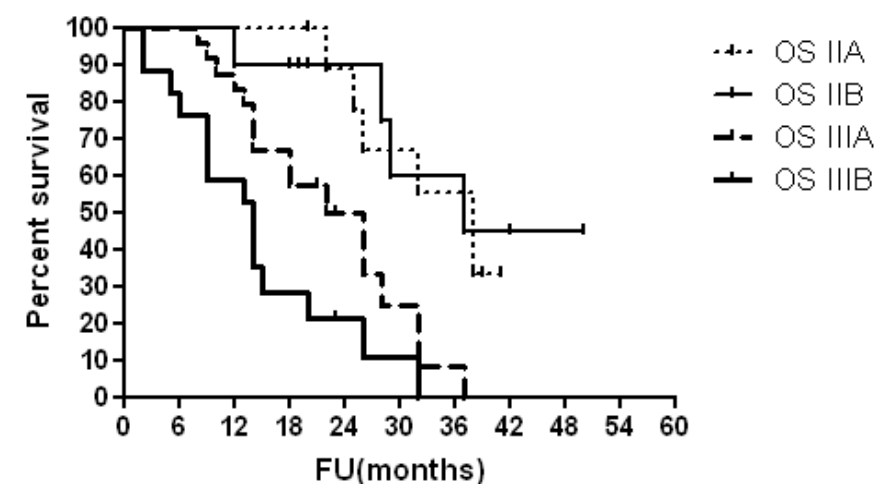

Figure 3. OS of patients treated by CRTwith respect to disease stage

\section{Discussion}

The majority of patients with esophageal cancer die from metastatic disease within three years of presentation, despite radical surgical resection (Bytzer et al., 1999), due to the presence of, occult metastatic cells that have disseminated before surgery (O'Sullivan et al., 1999). The concept of disseminated tumor cells that explains poor prognosis after surgical resection led to the development of CRT (Neuner et al., 2009).

Definitive CRT and CRT followed by surgery are well established in the curative treatment of patients with localized esophageal cancer (Urba et al., 2001; Abrams et al., 2009; Teoh et al., 2012) and those with locally advanced disease (Yano et al., 2002; Rades et al., 2007; Batirel et al., 2008).

Reported studies showed no significant differences in 2-year survival rates, of patients treated with definitive CRT compared to those treated with surgery alone (Chiu et al., 2005), and compared to patients treated with CRT and surgery (Stahl et al., 2005; Bedenne et al., 2007) and suggested that adding surgery conferred no additional benefit.

Most of the reported studies stated that, the possible gains with IMRT over three dimensional conformal radiation therapy (3DCRTH) could come from reduced toxicity and delivery of a higher dose to target volumes, with no survival advantage (Chandra et al., 2005; Freilich et al., 2013; Roeder et al., 2014). Accurate radiation dose calculation algorithms must apply tissue heterogeneity corrections that account for the electronic disequilibrium effect (caused by lung involvement) near tissue heterogeneity interface (Rana \& Rogers, 2013). The present study used 3DCRTH in the CRT group, and used Clarkson radiation dose calculation algorithm that is based on the principle that the scattered component of the depth dose, which depends on the field size and shape, can be calculated separately from the primary component, which is independent of the field size and shape (Khan, 2010). More accurate algorithms as Acuros XB and anisotropic analytical algorithms were developed for dose predictions when heterogeneous media are involved (Rana \& Rogers, 2013; Amankwaa-Frempong et al., 2014). 
The present study showed that, after a median follow up of 20 months; 2-year OS rate for the whole group was $46 \%$. There was significant differences in 2-year OS in favor of patients treated by concurrent chemoradiation (55.4\%) compared to those treated by esophagectomy $(31 \%)(\mathrm{p}=0.016)$. This superior survival rate in the chemoradiation group compared to surgery group could be attributed to a high 90 -day post-operative mortality and not to predominance of unfavorable prognostic factors such as advanced disease stages, and high grade disease in surgery group. Patients in both treatment groups were homogeneous as there were no significant difference regarding distribution of patients in both groups, according to age at diagnosis, gender, pathologic subtype, histologic grade, disease stage, and tumor site ( $p>0.05)$. This is in agreement with Siersema, (2008) who reported that three-month mortality, was higher in the surgery arm $(9.3 \%$ versus $0.8 \%, \mathrm{P}=0.002)$. In a reported study, the majority of patients in CRT group were both alive and recurrence free at 5 years, while in the surgery group, both overall survival and disease-free survival continued to deteriorate overtime (Teoh et al., 2012). This is also confirmed by results of a study conducted by Bedenne et al., (2002) who reported identical survival data between chemo-radiotherapy followed by surgery and definitive CRT groups, but mortality proved to be significantly lower in the definitive CRT group (without surgery). Surgery may play a role for salvage treatment for nonresponders in CRT group (Stahl et al., 2005).

In the present study, univariate analysis showed that 2-year OS rates were not significantly affected by patient's age, gender, pathologic subtype, and histologic grade, in patients treated by esophagectomy and CRT ( $\mathrm{p}>0.05)$. This is in agreement with reported studies (Sucimachi et al., 1986; Urba et al., 2001; Song et al., 2012).

Disease stage significantly affect OS rate in both groups ( $\mathrm{p}=0.0029$, and $\mathrm{p}<0.0001$ respectively). There was significant OS advantage in upper and middle thirds compared to lower third in CRT group $(\mathrm{p}=0.009)$ and a trend to survival advantage in surgery group $(\mathrm{p}=0.066)$. This is confirmed by reported studies (Sucimachi et al., 1986; Teoh et al., 2012; Song et al., 2012).

\section{Conclusions}

In patients with esophageal cancer, concurrent chemoradiation resulted in statistically significant higher OS rate than that achieved by esophagectomy. Disease stage in both treatment groups and tumor site in chemoradiation group significantly affected survival. A large scale prospective trial addressing CRT with IMRT and newer chemotherapeutic agents would be useful to determine the impact of improved radiation dose homogeneity on survival in patients with esophageal cancer.

\section{Competing Interests}

The authors declare that they have no competing interests.

\section{Authors' Contributions}

Mohamed I. El-Sayed participated in the patient diagnosis, chemo-radiation given to patients in CRT group, statistical analysis, manuscript drafting and writing the final manuscript. Doaa W. Maximous participated in the patient diagnosis, and esophagectomy in surgery group. Authors read and approved the final manuscript.

\section{References}

Abrams, J. A., Buono, D. L., Strauss, J., McBride, R. B., Hershman, D. L., \& Neugut, A. I. (2009). Esophagectomy compared to chemoradiation for early stage esophageal cancer in the elderly. Cancer, 115(21), 4924-4933. http://dx.doi.org/10.1002/cncr.24536

Amankwaa-Frempong, E., Vernimmen, F., Blay, S., \& Ezhilalan, R. (2014). Irradiation of lung and esophagus tumors:A comparison of dose distributions calculated by anisotropic analytical algorithm and pencil beamconvolution algorithm, a retrospective dosimetric study. Int J Cancer Ther Oncol, 2(2), 020210. http://dx.doi.org/10.14319/ijcto.0202.10

Batirel, H. F., Gemici, C., Yildizeli, B., Lacin, T., Akgul, A. G., Evman, S., Caglar, H. B., Ilhan, M., \& Yuksel, M. (2008). Results of transthoracic esophagectomy following chemoradiation in locally advanced esophageal cancer 20. Turkish Journal of Cancer, 38(1), 20-25.

Bedenne, L., Michel, P., Bouché, O. et al. (2007). Chemoradiation followed by surgery compared with chemoradiation alone in squamous cancer of the esophagus: FFCD 9102. J Clin Oncol, 25, 1160-1168. http://dx.doi.org/10.1200/JCO.2005.04.7118

Bedenne, L., Michel, P., Bouché, O., Triboulet, J. P., Conroy, T., Pezet, D. et al. (2002). Randomized phase III trial in locally advanced esophageal cancer: radio-chemotherapy followed by surgery versus radiochemotherapy alone (FFCD 9102). Proc Am Soc Clin Oncol, 21, 130a (abstract). 
Bytzer P, Christensen PB, Damkier P, Vinding K, \& Seersholm N (1999). Adenocarcinoma of esophagus and Barrett's esophagus: a population based study. Am J Gastroenterology, (94), 86-91.

Chandra, A., Guerrero, T. M., Liu, H. H., Tucker, S. L., Liao, Z., Wang, X., ... Komaki, R. (2005). Feasibility of using intensity-modulated radiotherapy to improve lung sparing in treatment planning for distal esophageal cancer. Radiotherapy and Oncology ;77, 247-253. http://dx.doi.org/10.1016/j.radonc.2005.10.017

Chiu, P. W., Chan, A. C., Leung, S. F. et al. (2005). Multicenter prospective randomized trial comparing standard esophagectomy with chemoradiotherapy for treatment of squamous esophageal cancer: early results from the Chinese University Research Group for Esophageal Cancer (CURE). J Gastrointest Surg, 9, 794-802. http://dx.doi.org/10.1016/j.gassur.2005.05.005

Cooper, J. S., Guo, M. D., Herskovic, A. et al. (1999). Chemoradiotherapy of locally advanced esophageal cancer: long-term follow-up of a prospective randomized trial (RTOG 85-01). Radiation Therapy Oncology Group. JAMA, 281(17), 1623-1627. http://dx.doi.org/10.1001/jama.281.17.1623

Fok, M., Sham, J. S. T., Choy, D., Cheng, S. W. K., \& Wong, J. (1993). Postoperative radiotherapy for carcinoma of the esophagus: a prospective, randomized controlled trial. Surgery, (113), 138-147.

Freilich, J., Chuong, M., Yue, B., Fulp, W. J., Abuodeh, Y. A., Almhanna, K., ... Shridhar, R. (2013). Comparative outcomes for 3D conformal versus intensity modulated radiation therapy for esophageal cancer. J Clin Oncol, 31(suppl 4; abstr 76).

Gebski, V., Burmeister, B., Smithers, B. M., et al. (2007). Australasian Gastro-Intestinal Trials Group. Survival benefits from neoadjuvant chemoradiotherapy or chemotherapy in oesophageal carcinoma: a meta-analysis. Lancet Oncol, 8, 226-234. http://dx.doi.org/10.1016/S1470-2045(07)70039-6

Herskovic, A., Martz, K., al-Sarraf, M., et al. (1992). Combined chemotherapy and radiotherapy compared with radiotherapy alone in patients with cancer of the esophagus. $N$ Engl J Med., 326(24), 1593-1598. http://dx.doi.org/10.1056/NEJM199206113262403

Khan, F. M. (2010). The Physics of Radiation Therapy (4th ed., pp. 460-462). Philadelphia, PA: Lippincott Williams \& Wilkins.

Kranzfelder, M., Schuster, T., Geinitz, H., et al. (2011). Meta-analysis of neoadjuvant treatment modalities and definitive non-surgical therapy for oesophageal squamous cell cancer. $B r J$ Surg; 98, 768-783. http://dx.doi.org/10.1002/bjs.7455

Minsky, B. D., Pajak, T. F., Ginsberg, R. J., et al. (2002). INT 0123 (Radiation Therapy Oncology Group 94-05) phase III trial of combined-modality therapy for esophageal cancer: high-dose versus standard-dose radiation therapy. J Clin Oncol., 20(5), 1167-1174. http://dx.doi.org/10.1200/JCO.20.5.1167

Neuner, G., Patel, A., \& Suntharalingam, M. (2009). Chemoradiotherapy for eophageal cancer. Gastrointest Cancer Res., 3(2), 57-65.

O'Sullivan, G., Sheahan, D., Clarke, A., Stuart, R., Walsh, T., Kelly, J., ... Shanahan, F. (1999). Micrometastases in esophagogastric cancer: high detection rate in resected rib segments. Gastroenterology, (116), 543-548. http://dx.doi.org/10.1016/S0016-5085(99)70175-7

Rades, D., \& Schild, S. (2007). Is surgery necessary following chemoradiation for patients with locally advanced cancer of the oesophagus? Nature Clinical Practice Oncology, 4(9). http://dx.doi.org/10.1038/ncponc0897

Rana, S., \& Rogers, K. (2013). Radiobiological evaluation of dose calculation algorithms in RapidArc planning of esophageal cancer treatment plans. Journal of Solid Tumors, 3, 44-52. http://dx.doi.org/10.5430/jst.v3n3p44

Ries, L. A. G., Melbert, D., Krapcho, M., et al (2008). SEER Cancer Statistics Review, 1975-2005, National Cancer InstituteBethesda, MD. based on November 2007 SEER data submission, posted to the SEER web site.

Roeder, F., Nicolay, N. H., Nguyen, T., Saleh-Ebrahimi, L., Askoxylakis, V., Bostel, T., .. Hoffe, S. E. (2014). Radiation Therapy and Esophageal Cancer. Cancer Control., 20(2), 97-110.

Shridhar R, Almhanna K, Meredith KL, Biagioli MC, Chuong MD, Cruz A \& Hoffe SE (2013). Radiation Therapy and Esophageal Cancer. Cancer Control.; 20(2):97 - 110.

Siersema, P. D. (2008). Esophageal cancer. Gastroenterol Clin $N$ Am, 37, 943-964. http://dx.doi.org/10.1016/j.gtc.2008.09.012 
Siewert, J. R., Stein, H. J., Feith, M., et al. (2001). Histologic tumor type is an independent prognostic parameter in esophageal cancer: lessons from more than 1,000 consecutive resections at a single center in the Western world. Ann Surg, 234, 360-369. http://dx.doi.org/10.1097/00000658-200109000-00010

Sjoquist, K. M., Burmeister, B. H., Smithers, B. M., et al. (2011). ustralasian Gastro-Intestinal Trials Group. Survival after neoadjuvant chemotherapy or chemoradiotherapy for resectable oesophageal carcinoma: an updated meta-analysis. Lancet Oncol, 12, 681-692. http://dx.doi.org/10.1016/S1470-2045(11)70142-5

Song, Z., Wang, J., Lin, B., \& Zhang, Y. (2012). Analysis of the tumor length and other prognosis factors in pT1-2 node-negative esophageal squamous cell carcinoma in a Chinese population. World Journal of Surgical Oncology, 10, 273. http://dx.doi.org/10.1186/1477-7819-10-273

Stahl, M., Stuschke, M., Lehmann, N. et al. (2005). Chemoradiation with and without surgery in patients with locally advanced squamous cell carcinoma of the esophagus. $J$ Clin Oncol, 23, 2310-2317. http://dx.doi.org/10.1200/JCO.2005.00.034

Sucimachi, K., Matsuura, H., Kai, H., Kanematsu, T., Inokuchi, K., \& Jingu, K. (1986). Prognostic factors of esophageal carcinoma: Univariate and multivariate analyses. Journal of Surgical Oncology, 31, 108-112. http://dx.doi.org/10.1002/jso.2930310207

Teoh, A. Y. B., Chiu, P. W. Y., Yeung, W. K., Liu, S. Y. W., Wong, S. K. H., \& Ng, E. K. W. (2012). Long-term survival outcomes after definitive chemoradiation versus surgery in patients with resectable squamous carcinoma of the esophagus: results from a randomized controlled trial. Annals of Oncology, 00, 1-7. http://dx.doi.org/10.1093/annonc/mds206

Urba, S. G., Orringer, M. B., Turrisi, A., Iannettoni, M., Forastiere, A., \& Strawderman, M. (2001). Randomized Trial of Preoperative Chemoradiation Versus Surgery Alone in Patients With Locoregional Esophageal Carcinoma. J Clin Oncol, 19(2), 305-313.

Wong, R., \& Malthaner, R. (2006). Combined chemotherapy and radiotherapy (without surgery) compared with radiotherapy alone in localized carcinoma of the esophagus. Cochrane Database Syst Rev., (1), CD002092. http://dx.doi.org/10.1002/14651858.CD002092

Yano, M., Inoue, M., \& Shiozaki, H. (2002). Preoperative Concurrent Chemotherapy and Radiation Therapy Followed by Surgery for Esophageal Cancer. Ann Thorac Cardiovasc Surg, 8(3), 123-130.

Zieren, H. U., Müller, J. M., Jacobi, C. A., Pichlmaier, H., Müller, R.-P, \& Staar, S. (1995). Adjuvant postoperative radiation therapy after curative resection of squamous cell carcinoma of the thoracic esophagus: a prospective randomized study. World $J$ Surg., (19), 444-449. http://dx.doi.org/10.1007/BF00299187

\section{Copyrights}

Copyright for this article is retained by the author(s), with first publication rights granted to the journal.

This is an open-access article distributed under the terms and conditions of the Creative Commons Attribution license (http://creativecommons.org/licenses/by/3.0/). 